\title{
Preparation and Characterization of Sansevieria trifasciata Fiber/High- Impact Polypropylene and Sansevieria trifasciata Fiber/Vinyl Ester Biocomposites for Automotive Applications
}

\author{
Apang Djafar Shieddieque ${ }^{1,2}$, Mardiyati ${ }^{1 *}$, Rochim Suratman ${ }^{1}$, Bambang Widyanto ${ }^{1}$ \\ ${ }^{1}$ Faculty of Mechanical and Aerospace Engineering, Institut Teknologi Bandung, Ganesha 10, Bandung \\ 40132, Indonesia \\ ${ }^{2}$ Faculty of Mechanical Engineeing, Sekolah Tinggi Teknologi Wastukancana, Jalan Cikopak No.53, \\ Mulyamekar, Purwakarta 41151, Indonesia
}

\begin{abstract}
The increasing demand for vehicles is resulting in environmental problems, such as a higher demand for fossil fuels and higher $\mathrm{CO}_{2}$ emissions. Lightweight materials, such as fiberreinforced polymers, have been used in automotive components to reduce the weight, fuel consumption, and $\mathrm{CO}_{2}$ emissions of vehicles. Natural fibers are often used as substitutes for glass fibers because they are abundant and require less energy to produce compared to glass fibers. The present research focused on the preparation and characterization of composites reinforced with Sansevieria trifasciata fiber (STF). High-impact polypropylene (HIPP) and vinyl ester (VE) were chosen and compared as matrix materials. The results showed that the mechanical properties of the produced biocomposites increased with increasing amounts of fiber, alkaline treatment, and unidirectional fiber orientation. A tensile strength of $59.77 \mathrm{MPa}$ and a stiffness of $1.97 \mathrm{GPa}$ were obtained for STF/HIPP composites with unidirectional alkali treatment and a 15\% volume fraction of fiber. Moreover, a tensile strength of $121.1 \mathrm{MPa}$ and a stiffness of 7.65 GPa were obtained for STF/VE composites with unidirectional alkali treatment and a 15\% volume fraction of fiber. The STF/VE biocomposites were comparable to commercial glass fiber composites for automotive applications and even exhibited greater tensile strength properties.
\end{abstract}

Keywords: Biocomposites; High-impact polypropylene; Sansevieria trifasciata; Vinyl ester

\section{Introduction}

The increasing use of vehicles such as cars and motorcycles is causing environmental problems, such as high $\mathrm{CO}_{2}$ emissions and a fossil fuel shortage. Lightweight materials, such as fiber-reinforced polymers, have been used in automotive components to reduce the weight, fuel consumption, and $\mathrm{CO}_{2}$ emissions of vehicles (Ramesh et al., 2017). Fiberreinforced polymers exhibit excellent mechanical properties. However, the use of glass fibers for reinforcement can bring about other environmental problems, as these fibers are non-degradable and require high energy for processing. Natural fibers are often used as substitutes for glass fibers because they are abundant and require less energy to produce compared to glass fibers. Recently, the utilization of polymers reinforced with natural fibers or biocomposites has been growing, especially for interior and exterior parts in the

${ }^{*}$ Corresponding author's email: mardiyati@material.itb.ac.id, Tel.: +62-22-2504243, Fax.: +62-22-2534099 doi: 10.14716/ijtech.v12i3.2841 
automotive industry (Thakur and Thakur, 2014; Väisänen et al., 2016). Biocomposites offer many advantages, such as high strength, low weight, biodegradability, corrosion resistance, and low cost (Sreenivasan et al., 2011; Najafi, 2013). Natural fibers are also biodegradable because they attract microorganisms (Surip and Jaafar, 2018). Some products for instance sports equipment, electronic housing or vehicle panel have been reported to use natural fibers, such as hemp, banana, kenaf, wood, and pulp fibers (Miléo et al., 2011; Faruk et al., 2012; Suharty et al., 2016; Ramesh et al., 2017; Sharath Shekar and Ramachandra, 2018). For example, Fatra et al. (2016) reported on the properties of alkaline-treated oil palm empty fruit bunch fiber-reinforced polypropylene composites. The results showed that the highest tensile strength (20.1 MPa) was achieved with an alkaline concentration of $5 \mathrm{wt} . \%$, a soaking time of $36 \mathrm{~h}$, and $3-\mathrm{cm}$ fibers. In this case, the utilization of natural fibers is likely to decrease pollution and other environmental problems. Natural fiber materials have been proven to serve as effective alternatives to glass fiber reinforcement polymers.

According to the literature, natural fiber-reinforced composites (or biocomposites) exhibit mechanical properties comparable to those of glass fibers. More specifically, some studies have shown that the mechanical properties of flax, hemp, jute, and sisal fibers can compete with those of glass fibers (Gurunathan et al., 2015). Other research has shown that tensile and modulus properties tend to increase with increasing fiber volume fractions (Sankar et al., 2014). Although glass fiber is the primary reinforcement material used in composites for automotive applications, biocomposites have shown good potential for future development. The energy requirements for processing glass fiber exceed those of natural fiber. For example, 6,500 BTUs of energy are required to produce a single pound of kenaf fiber, whereas 23,000 BTUs are required to produce a single pound of glass fiber (Akampumuza et al., 2017). Over the last two decades, many works have aimed to apply biocomposites for automotive purposes. Furthermore, many researchers have reported on the advantages of natural fibers, such as their availability, non-toxicity, renewability, costeffectiveness, and mechanical properties (e.g., toughness, strength, and stiffness; Rajak et al., 2019). Examples of biocomposite applications in the automotive industry include the rear panel shelves of the Mercedes-Benz C-Class models built in South Africa (made from sisal-reinforced composite), the inner door panels of the Opel Corsa (made from flaxreinforced polypropylene composites), and the interior door linings and panel of the BMW 7 Series (made using $24 \mathrm{~kg}$ of renewable materials). The use of natural fiber-based composites can reduce the weight of vehicles by 10-15\% (Akampumuza et al., 2017).

In the present work, natural fiber biocomposites were derived from Sansevieria trifasciata, commonly called the "lidah mertua (in-law's tongue)" plant. This plant is plentiful in Asia and Africa and is often used for decoration. Several studies have discussed the potential use of Sansevieria trifasciata for reinforcement in a polymer matrix. Sreenivasan et al. (2012) investigated the tensile, flexural, and impact properties of randomly oriented short Sansevieria cylindrical fiber/polyester (SCFP) composites. Mechanical property tests revealed that these composites had a tensile strength of approximately $76 \mathrm{MPa}$, a Young's modulus of $1.1 \mathrm{GPa}$, and an elongation at break between $7 \%$ and $8.3 \%$. The flexural strength of these composites was $84 \mathrm{MPa}$, the flextural modulus was $3 \mathrm{GPa}$, and the impact strength was $9.5 \mathrm{~J} / \mathrm{cm}^{2}$. Venkatachalam et al. (2016) investigated the tensile properties of Sansevieria trifasciata fiber (STF)-reinforced polyester composites with five different fiber lengths $(2,4,6,8$, and $10 \mathrm{~mm})$. The results showed that tensile strength increased as the fiber length increased. However, the elongation at break was not significantly affected by the fiber length. The highest tensile strength (40 MPa) was found at a fiber length of $10 \mathrm{~mm}$. Mardiyati et al. (2016) studied the effects of alkali treatment on the mechanical and thermal properties of STF. Chesson-Datta methods were used to 
determine the lignocellulose content of raw Sansevieria fibers and to investigate the effect of alkali treatment on the lignin content of these fibers. The obtained cellulose and lignin contents were $56 \%$ and $6 \%$, respectively. Mechanical testing showed that the tensile strength increased from $647 \mathrm{MPa}$ for raw fibers to $902 \mathrm{MPa}$ for $5 \mathrm{wt} \% \mathrm{NaOH}$-treated fibers. Zakaria et al. (2018) investigated the effects of fiber size $(1 \mathrm{~mm}, 500 \mu \mathrm{m}, 250 \mu \mathrm{m}$, and 125 $\mu \mathrm{m}$ ) on the mechanical, morphological, and thermal properties of STF/natural rubber/highdensity polyethylene (STF/NR/HDPE). The results showed that tensile strength and impact strength decreased and tensile modulus increased as filler loading increased. Furthermore, a fiber size of $125 \mu \mathrm{m}$ produced the highest and most stable tensile strength and modulus values. However, previous results have not yet met the mechanical requirements for automotive applications. For comparison, the mechanical properties of commercial glass fiber composite include a tensile strength of $85 \mathrm{MPa}$, a modulus of elasticity or stiffness of $10.2 \mathrm{GPa}$ in the $26 \mathrm{wt} . \%$ polyester resin matrix system, $28 \mathrm{wt} \%$ glass fiber, and $46 \mathrm{wt} . \%$ minerals with an average density of $1,801 \mathrm{~kg} \mathrm{~m}^{-3}$ (Xia et al., 2016).

The present research aimed to develop STF biocomposites that would meet automotive application requirements in high-impact polypropylene (HIPP) and vinyl ester (VE) matrices. The selection of these materials was based on their relatively strong mechanical properties, as it is necessary to develop biocomposites with strong mechanical properties. The effects of fiber orientation and fiber content on mechanical properties were investigated as well. Finally, the mechanical properties (e.g., tensile strength, stiffness, and impact toughness) of these composites were analyzed and compared with those of a commercial-grade fiber-reinforced composite.

\section{Methodology}

\subsection{Materials}

The Sansevieria trifasciata leaves used in this study were sourced from Beluk, East Java. For the alkaline treatment, a $3 \% \mathrm{NaOH}$ solution was prepared using commercial-grade $\mathrm{NaOH}$ from Bratachem. The matrices used to fabricate the biocomposites included VE from Bratachem and HIPP from Chandra Asri. The properties of these matrices are shown in Table 1.

Table 1 Properties of the polymer matrices used in this study

\begin{tabular}{|c|c|c|c|c|c|c|c|}
\hline \multirow[b]{2}{*}{ Matrix } & \multicolumn{5}{|c|}{ Properties } & \multirow[b]{2}{*}{ Supplier } & \multirow[b]{2}{*}{ Reference } \\
\hline & $\begin{array}{l}\text { Density } \\
\left(\mathrm{kg} / \mathrm{m}^{3}\right)\end{array}$ & $\begin{array}{l}\text { Melting } \\
\text { Point } \\
\left({ }^{\circ} \mathrm{C}\right)\end{array}$ & $\begin{array}{c}\text { Izod } \\
\text { Impact } \\
\text { Strength } \\
(\mathrm{J} / \mathrm{m})\end{array}$ & $\begin{array}{c}\text { Tensile } \\
\text { Strength } \\
(\mathrm{MPa})\end{array}$ & $\begin{array}{c}\text { Elongation } \\
\text { (\%) }\end{array}$ & & \\
\hline HIPP & 900 & 163 & 650 & 26 & 12 & Chandra Asri & $\begin{array}{c}\text { Technical } \\
\text { Data Sheet } \\
\text { (TDS) }\end{array}$ \\
\hline VE & 1,150 & $104-121^{*}$ & $250^{*}$ & $69-83^{*}$ & $4-7^{*}$ & Bratachem & $\begin{array}{l}{ }^{*} \text { (Holbery } \\
\text { and Houston } \\
2006)\end{array}$ \\
\hline
\end{tabular}

\subsection{Methods}

The Sansevieria fibers were taken from the leaves using a mechanical retting method and then rinsed with water to remove any leaf components. Then, the fibers were left to dry at room temperature for one day. The lignocellulose content of the fibers was measured using the Chesson-Datta method. Next, the fibers underwent alkaline treatment. In the alkaline treatment process, 10 grams of STF were put into reflux with the $3 \% \mathrm{NaOH}$ solution 
at $100^{\circ} \mathrm{C}$, with a fiber-to-solution ratio of 1:100 (Mardiyati et al., 2016). The heating process was carried out in two hours. Finally, the fibers were washed and neutralized with demineralized aqua and then dried at room temperature for one day. A schematic of the fiber preparation process is presented in Figure 1.

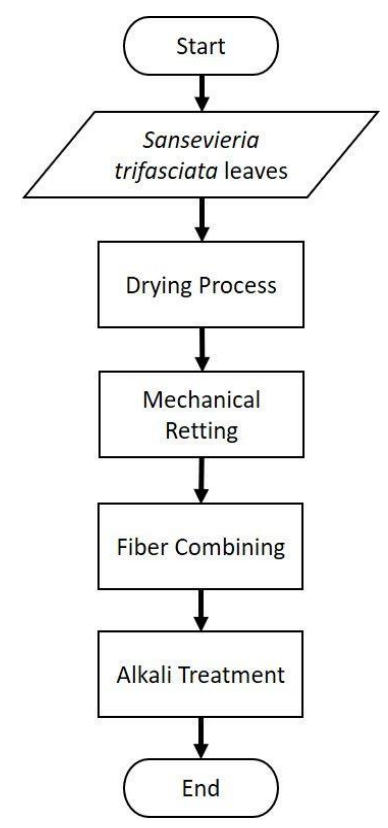

Figure 1 Schematic of the Sansevieria trifasciata fiber preparation process

The STF/HIPP biocomposites were made using hot compression molding at $180^{\circ} \mathrm{C}$ with 140 bars of pressure for 10 minutes. Meanwhile, the STF/VE biocomposites were made using compression molding at room temperature with 140 bars of pressure for 10 minutes and an aging time of two hours (Shieddieque et al., 2019). The fibers were arranged in unidirectional and random orientations with fiber volume fractions of $0 \%, 5 \%, 10 \%$, and $15 \%$. Figure 2 shows the preform biocomposites that resulted from the hot compression molding process with unidirectional and random fiber orientations.

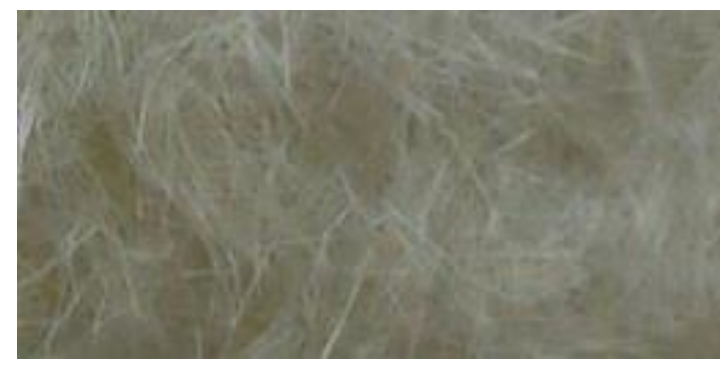

(a)

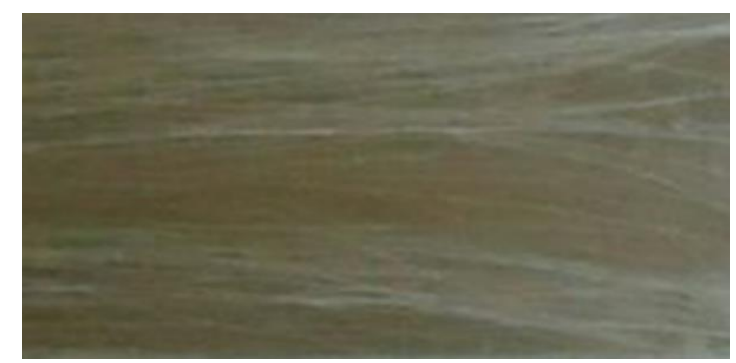

(b)

Figure 2 Preform biocomposites with: (a) unidirectional orientation; and (b) random orientation

The preform biocomposites were cut into $150 \times 25 \times 1.5 \mathrm{~mm}$ sections for the tensile test. The tensile test was carried out using a Tensilon RTF-1310 machine according to the American Standard for Testing and Material (ASTM) D3039 standard, with a gauge length of $100 \mathrm{~mm}$ and a crosshead speed of $2 \mathrm{~mm} \mathrm{~min}^{-1}$. The average tensile strength and elongation at break values were obtained from three specimens. The impact test was carried out using a Tinius Olsen impact testing machine. The composites were cut into 125 $\mathrm{cm} \times 8 \mathrm{~cm} \times 8 \mathrm{~cm}$ sections with a $45^{\circ} \mathrm{v}$-notch in accordance with ASTM D6110-04. 
The densities of the biocomposites were determined in accordance with ASTM D792, and the constituent contents were determined in accordance with ASTM D3171. The fiber and fracture surface morphologies of the biocomposites were investigated using a JEOL JSM-6510 scanning electron microscope (SEM) with an accelerating voltage of $20 \mathrm{kV}$. The spectrum of functional groups of the STF was investigated using fourier transform infrared spectroscopy (FTIR). The moisture content of the fibers was determined in accordance with ASTM D2654.

\section{Results and Discussion}

\subsection{Characterization of Sansevieria trifasciata Fiber (STF)}

Lignocellulose describes all constituents containing cellulose, hemicellulose, and lignin. Although lignocellulose can be found in all parts of a plant's body, different percentages of lignocellulose content can be found in different parts and types of plants. Among the components of lignocellulose, cellulose is more desirable than hemicellulose or lignin. Therefore, an alkali treatment process is often carried out to obtain cellulose in a pure phase by dissolving lignin and hemicellulose. The high availability, good mechanical properties, and high degradation ability of cellulose make it worthy of utilization in the world of technology.

Table 2 shows the composition of lignocellulose in STF and other types of fiber. Although the hemicellulose content of STF is higher than that of other types of fiber, cellulose is the main constituent of STF; thus, STF can potentially be used to reinforce polymers. In the present study, hemicellulose and lignin were removed from STF through alkaline treatment (Mardiyati et al., 2016). The effects of alkaline treatment on fiber morphology have been discussed by other researchers (Shiddieque et al., 2018), and the morphologies of treated and untreated fibers can be seen elsewhere (Shieddieque et al., 2018). The surfaces of the alkaline-treated fibers became rougher than those of the untreated fibers. This condition improved the properties of the interface between the fibers and the matrices. Specifically, this roughness improved the interlocking between the fibers and the matrices and thus significantly increased the mechanical properties of the composites. Table 3 shows the improvements in mechanical properties exhibited by the STF after alkaline treatment. Furthermore, the results showed higher tensile strength and stiffness than other references. The tensile strength of the fibers contributed to the tensile strength of the composites according to the rule of mixtures (ROM). However, the ROM method can be applied based on assumptions, such as those of a homogeneous matrix, a lack of any voids, homogenous fibers, and good fiber arrangement in space (You et al., 2017). In the present study, the moisture content of the STF was $10 \%$. However, some studies have reported natural fiber moisture contents in the range of 7-13\% (Faruk et al., 2012; Wolela, 2019).

Table 2 Composition of Sansevieria trifasciata fiber (STF) compared to references

\begin{tabular}{cccccc}
\hline \multirow{2}{*}{ Fiber } & \multicolumn{4}{c}{ Composition (\%) } & \multirow{2}{*}{ Reference } \\
\cline { 2 - 5 } & Hemicellulose & Cellulose & Lignin & Hot water soluble & \\
\cline { 2 - 4 } STF & 33 & 55 & 9 & 3 & Thakur and \\
Flax & 21 & 71 & 2 & 6 & Thakur (2014) \\
Sisal & 14 & 73 & 11 & 2 & Thakur and \\
Thakur $(2014)$
\end{tabular}


Figure 3 shows the spectrum of functional groups of the STF before and after alkaline treatment, which was obtained through FTIR testing. The FTIR characterization results for the STF before and after alkaline treatment were normalized against the $896 \mathrm{~cm}^{-1}$ peaks, which correlated with the $\beta$-glucopyranose group on cellulose. The results indicated a decrease in absorbance at 1245, 1508, and $1760 \mathrm{~cm}^{-1}$ on the FTIR curve after alkaline treatment. This means that the hemicellulose and lignin in the fibers were reduced after alkaline treatment. The decrease in the peak at $1760 \mathrm{~cm}^{-1}$ indicates the presence of an ester group. The reduction in the ester group is closely related to the reduction of the $\mathrm{C}=0$ functional group, which can generally be found in hemicellulose. The decrease at $1508 \mathrm{~cm}^{-1}$ is closely related to the decrease in $\mathrm{C}=\mathrm{C}$, which is commonly found in lignin. Based on the FTIR characterization results (Figure 3), it can be concluded that the non-cellulose content of STF will decrease after alkaline treatment.

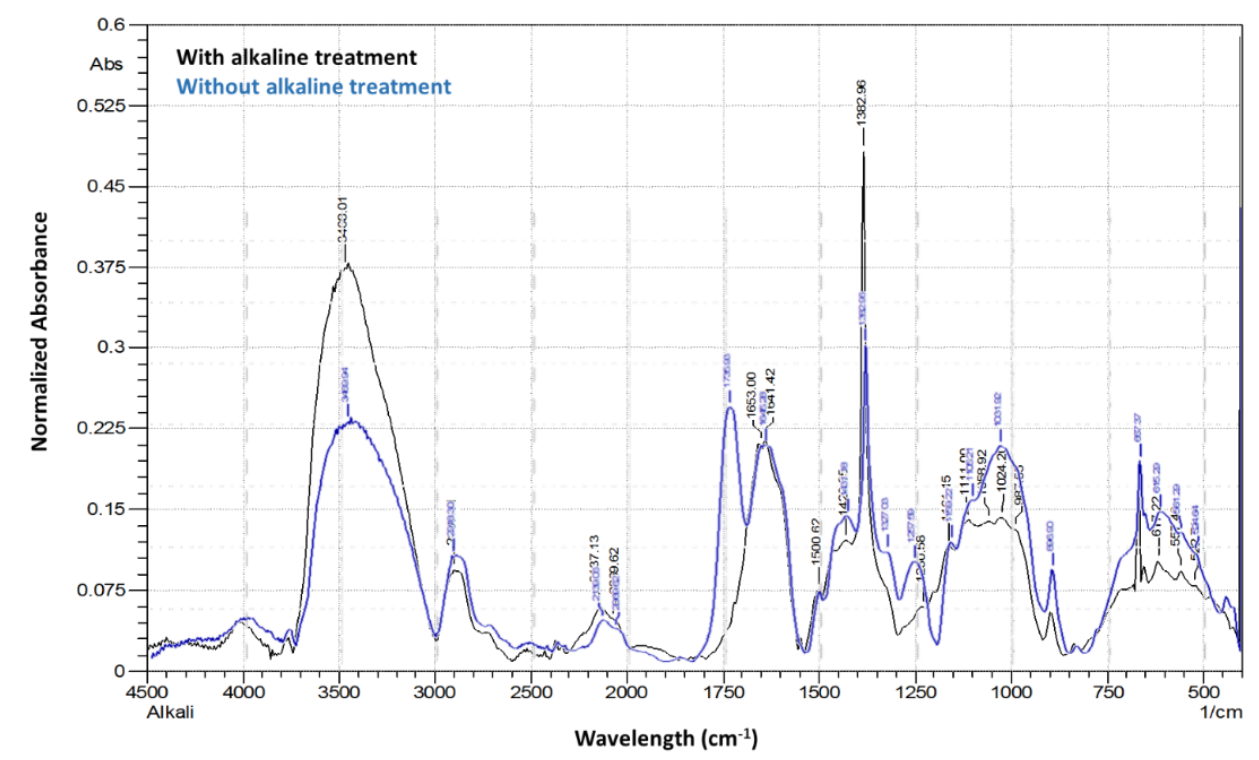

Figure 3 Fourier transform infrared spectroscopy (FTIR) results for Sansevieria trifasciata fiber (STF) before and after alkaline treatment

Table 3 The properties of Sansevieria trifasciata fiber (STF) compared to references

\begin{tabular}{lccccl}
\hline \multicolumn{1}{c}{ Fiber } & $\begin{array}{c}\text { Density } \\
\left(\mathrm{kg} / \mathrm{m}^{3}\right)\end{array}$ & $\begin{array}{c}\text { Diameter } \\
(\mu \mathrm{m})\end{array}$ & $\begin{array}{c}\text { Tensile } \\
\text { Strength } \\
(\mathrm{MPa})\end{array}$ & $\begin{array}{c}\text { Young's } \\
\text { Modulus } \\
(\mathrm{GPa})\end{array}$ & Reference \\
\hline Untreated STF & 1,100 & 64.3 & 596 & 19.3 & \\
Alkaline-treated STF & 1,300 & 38.8 & 772 & 24.1 & \\
STF & 1,200 & - & $647-919$ & 20.7 & Pickering (2008) \\
STF & 890 & $83-93$ & $526-598$ & $13.5-15.3$ & Sanjay et al. (2018) \\
Jute & 1,460 & - & $393-800$ & $10-30$ & Sanjay et al. (2018) \\
Sisal & 1,450 & $50-300$ & $227-400$ & $9-20$ & Sanjay et al. (2018) \\
Ramie & 1,500 & - & 560 & 24.5 & Faruk et al. (2012) \\
Kenaf & - & & 930 & 53 & Faruk et al. (2012) \\
Pineapple & $800-1,600$ & & $400-627$ & 1.44 & Faruk et al. (2012) \\
\hline
\end{tabular}

\subsection{Mechanical Properties of STF/HIPP and STF/VE Biocomposites}

To achieve good biocomposite performance, it is essential to understand the effects of natural fibers on the mechanical properties of biocomposites. Mechanical propertiesincluding tensile strength, modulus elasticity, impact strength, hardness, and toughness- 
are useful for the classification of materials for various applications. The mechanical properties of biocomposites generally depend on the matrix material, the orientation of the fibers, the volume fraction of the fibers, and the interfaces between the matrix and the reinforcement. In the present study, the mechanical properties of biocomposites were tested with a tensile test and an impact test. Tensile properties are the most essential mechanical properties of biocomposites, as they indicate the average properties throughout the entire thickness of a biocomposite. Modulus elasticity is a mechanical property that indicates the stiffness of a solid material, defining the relationship between stress (force per unit area) and strain (proportional deformation) within the material. Moreover, an impact test indicates the ability of a material to resist fracture under stress applied at high speed. Poor impact strength is often listed as a major disadvantage of biocomposite properties. For example, the impact strength of bamboo/ polyactic acid (PLA) composite has been shown to decrease after the addition of bamboo fibers (Faruk et al., 2012). Additionally, the formation of a cavity during mold casting can reduce the impact strength of a composite (Pramono et al., 2017). However, impact strength tends to increase significantly after fiber treatment (Shieddieque et al., 2018). High impact strength is the result of good fiber and matrix adhesion, which effectively inhibits crack propagation (Huda et al., 2008).

Figure 4 displays the effects of fiber content and fiber orientation on the mechanical properties of STF/HIPP and STF/VE composites. In general, mechanical properties-such as tensile strength, stiffness (Young's modulus), and impact toughness-increased significantly as the fiber volume fraction increased.

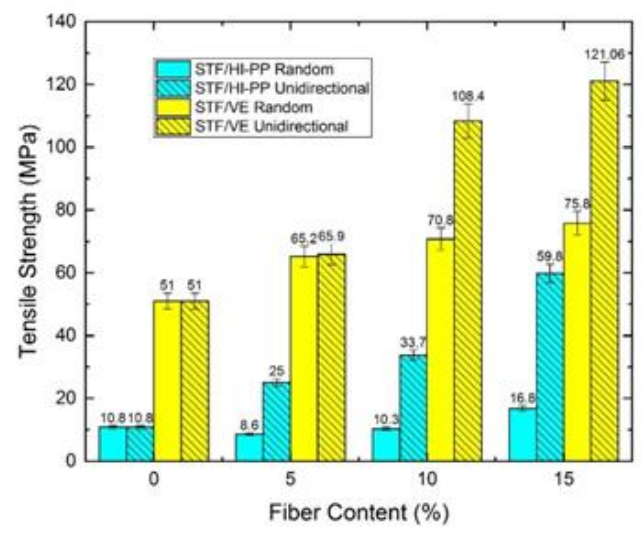

(a)

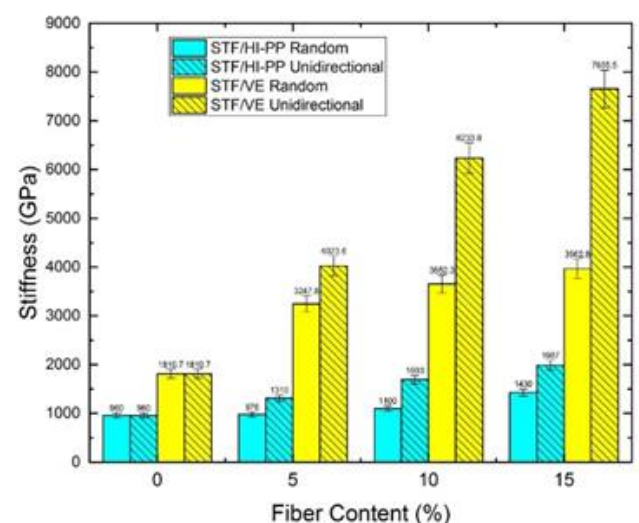

(b)

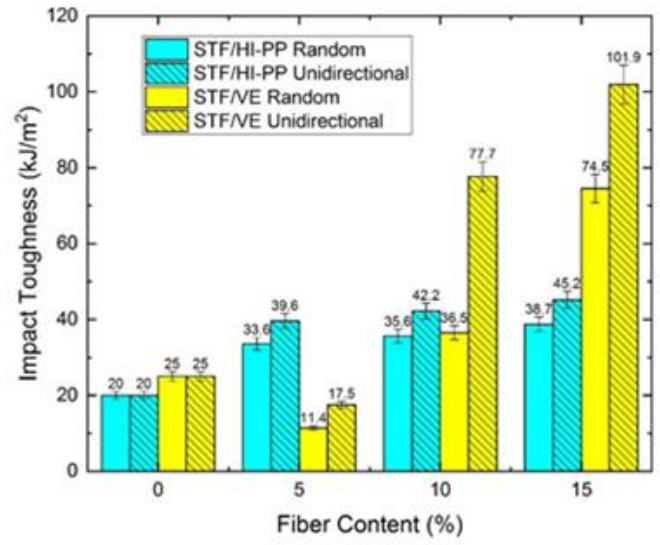

(c)

Figure 4 Mechanical properties of biocomposites as a function of fiber content: (a) tensile strength; (b) stiffness; and (c) impact toughness 
Notably, a unidirectional fiber orientation and 15\% fiber volume yielded the strongest mechanical properties for both the STF/HIPP and STF/VS biocomposites. Meanwhile, the biocomposites with random fiber orientations showed less mechanical property improvement than those with unidirectional fiber orientations. The strong mechanical properties of the unidirectional fiber orientation might have been due to the high fiber density along the tensile direction, which enabled a mechanical interlocking mechanism and thus improved the mechanical properties of the biocomposites. Moreover, the ROM explains that higher fractions of fiber increase the strength and stiffness of areas close to the fibers, which are higher than the strength and stiffness of the matrix.

Figure 4 compares the mechanical properties of two different types of matrices: thermoplastic and thermosetting matrices. The thermoplastic matrix is represented by HIPP, and the thermosetting matrix is represented by VE. The biocomposite with a thermoset matrix (i.e., STF/VE) had stronger mechanical properties than the STF/HIPP biocomposite; this result was consistent with the initial natural properties of the thermoset matrix. The mechanical properties of the biocomposites created in the present study were compared with a commercial-grade glass fiber composite for automotive applications described by Xia et al. (2016). The mechanical properties of the commercial glass fiber composite included a tensile strength of $85 \mathrm{MPa}$, a modulus of elasticity or stiffness of 10.2 $\mathrm{GPa}$, a $26 \mathrm{wt} . \%$ polyester resin matrix system, $28 \mathrm{wt} \%$ glass fiber, and $46 \mathrm{wt} . \%$ minerals with an average density of $1,801 \mathrm{~kg} \mathrm{~m}^{-3}$. The tensile strength of the STF/VE biocomposite with 15 vol.\% fiber was $121 \mathrm{MPa}$, and the stiffness (modulus elasticity) of this biocomposite was 7.6 GPa. Thus, the tensile strength of the STF/VE biocomposite exceeded that of the commercial-grade glass fiber composite, and the modulus elasticity or stiffness of the $\mathrm{STF} / \mathrm{VE}$ biocomposite was near that of the glass fiber composite.

\subsection{Density and Pore Measurement Analysis}

Figure 5a shows the density and void measurement results of the biocomposites. All of the composites had density values above those of their matrices, which were $895 \mathrm{~kg} / \mathrm{m}^{3}$ for the HIPP and $1,150 \mathrm{~kg} / \mathrm{m}^{3}$ for the VE.

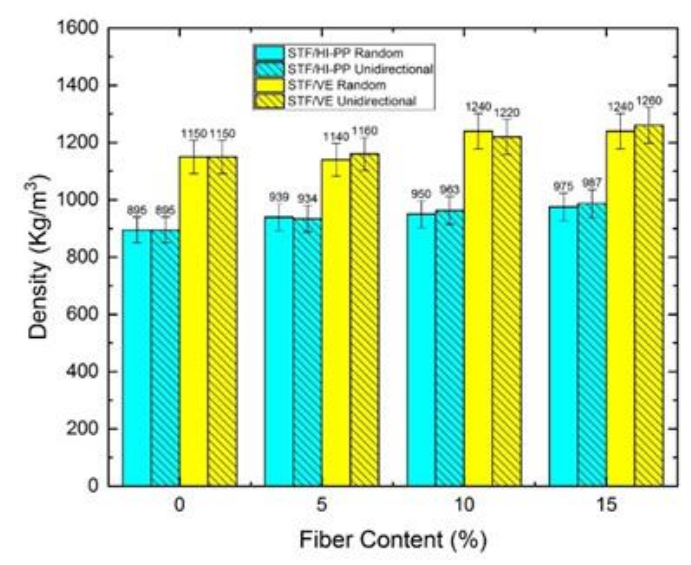

(a)

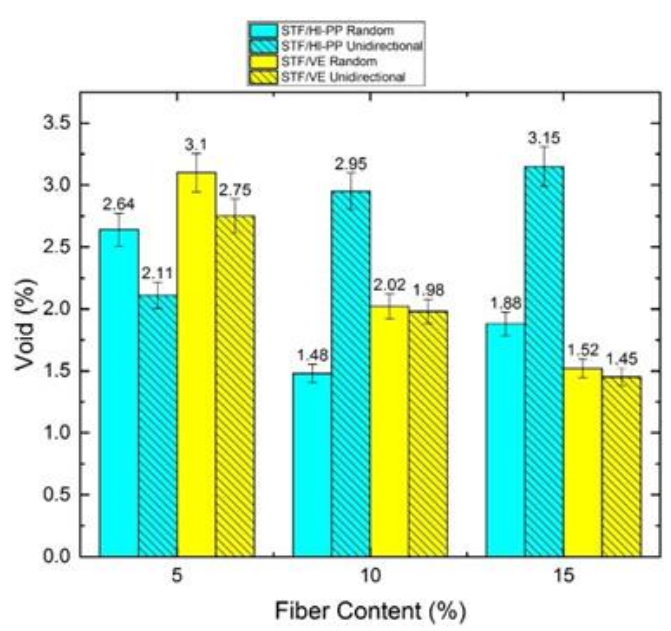

(b)

Figure 5 Measurement results for: (a) density; and (b) void content

Theoretically, STF/HIPP composites should have densities of $895-1,100 \mathrm{~kg} / \mathrm{m}^{3}$ for composites with non-alkali fibers and $895-1,300 \mathrm{~kg} / \mathrm{m}^{3}$ for composites with alkali fibers. Moreover, STF/VE composites should have densities of 1,100-1,150 kg/m $\mathrm{m}^{3}$ for composites with non-alkali fibers and $1,150-1,300 \mathrm{~kg} / \mathrm{m}^{3}$ for composites with alkali fibers. In the 
present case, the produced composites met the rule of the mixture equation for composite density. The densities of the STF/HIPP and STF/VE biocomposites increased by approximately $10 \%$ with increasing fiber content up to 15 vol.\%. Meanwhile, fiber orientation appeared to have no significant effects on the densities of the biocomposites.

Figure $5 \mathrm{~b}$ illustrates the void percentages in the biocomposites. In the STF/VE biocomposite, the void decreased with increasing fiber content. Fiber orientation had no significant effect on the void. Meanwhile, the STF/HIPP biocomposite showed irregular results. This irregularity might have been caused by the fabrication process, which was difficult to control. A void can be caused by non-homogeneous fiber interconnection or poor adhesion between the matrix and the fibers. In the present study, the strongest mechanical properties were obtained with the lowest void content. Low void content indicates good adhesion between the matrix and the fibers, which results in strong mechanical properties.

\subsection{Fracture Surface Morphology, as Indicated by Scanning Electron Microscope (SEM) Analysis}

Figure 6 shows the fracture surface morphologies of the STF/VE biocomposites, which were observed using an SEM. Figure 6a displays the fracture surface of the randomly oriented STF/VE biocomposite, while Figure $6 \mathrm{~b}$ shows the fracture surface of the unidirectionally oriented STF/VE biocomposite. Fiber pull-out was observed more frequently in the randomly oriented biocomposite than in the unidirectionally oriented biocomposite. Broken fibers were found on the fracture surface of the unidirectionally oriented biocomposite, indicating higher strength and stiffness. This result was consistent with the mechanical property results, which showed that the STF/VE biocomposite with a unidirectional fiber orientation exhibited higher properties values than that with a random fiber orientation.

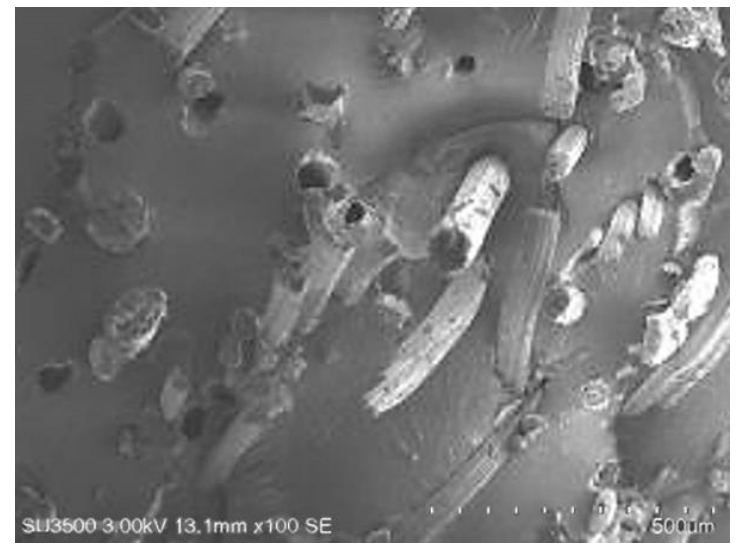

(a)

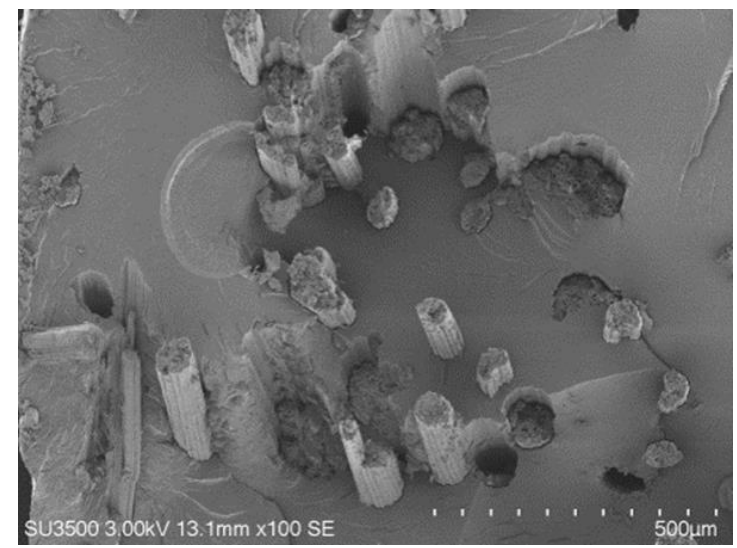

(b)

Figure 6 SEM images of the fracture surfaces of STF/VE biocomposites with: (a) random fiber orientation; and (b) unidirectional fiber orientation

The same phenomenon was observed in the STF/HIPP biocomposite, as shown in Figures $7 \mathrm{a}$ and $7 \mathrm{~b}$. Fiber pull-out was observed more frequently in the STF/HIPP biocomposite with a random fiber orientation, and broken fibers were observed more frequently on the STF/HIPP biocomposite with a unidirectional fiber orientation. Ramesh et al. (2017) reported similar characteristics in banana fiber-reinforced composites. The tensile rupture surfaces of unmodified banana fiber-reinforced composites exhibited fiber debonding, which left holes that indicated weak adhesion between the fibers and the matrix. On the other hand, the rupture surfaces of treated banana fiber-reinforced composites exhibited 
fiber breakage rather than pull-out, indicating good interfacial strength. In the present study, unidirectional fiber orientation corresponded to better adhesion between the fibers and the matrix, which led to higher tensile strength.

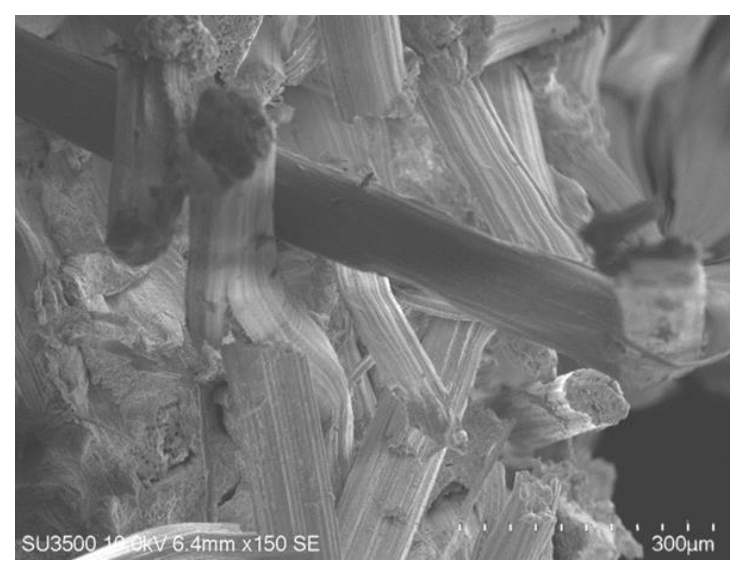

(a)

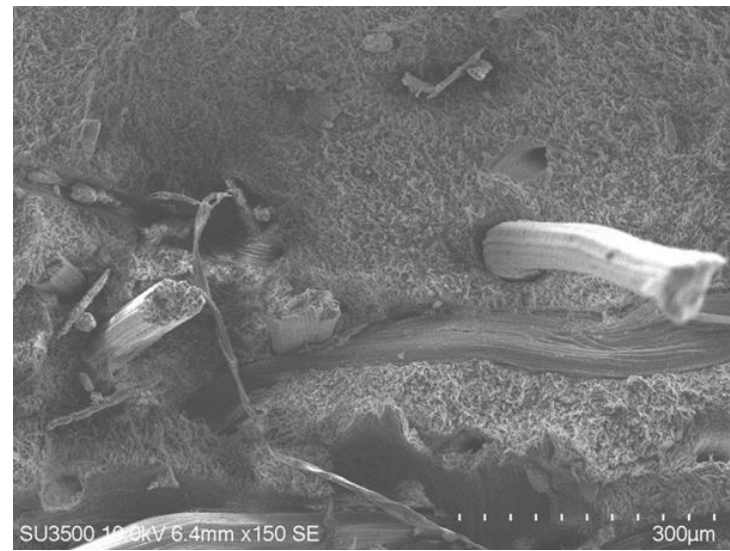

(b)

Figure 7 SEM images of the fracture surfaces of STF/HIPP biocomposites with a) random fiber orientation and $b$ ) unidirectional fiber orientation

\section{Conclusions}

The mechanical properties of the produced biocomposites improved with increased fiber content, alkaline treatment, and unidirectional fiber orientation. A tensile strength of 59.77 MPa and a stiffness of $1.97 \mathrm{GPa}$ were obtained for the STF/HIPP composite with a unidirectional orientation, alkali treatment, and a 15\% volume fraction of fiber. Moreover, a tensile strength of $121.1 \mathrm{MPa}$ and a stiffness of $7.65 \mathrm{GPa}$ were obtained for the STF/VE composite with a unidirectional orientation, alkali treatment, and a $15 \%$ volume fraction of fiber. The tensile strength of the STF/VE biocomposite exceeded that of a commercialgrade glass fiber composite ( $85 \mathrm{MPa})$, and the modulus elasticity or stiffness of this biocomposite was near that of the glass fiber composite (10.2 GPa). This means that STF shows good potential for future use in automotive applications.

\section{Acknowledgements}

The authors are thankful to PT Chandra Asri Petrochemical for providing the HIPP used in this research.

\section{References}

Akampumuza, O., Wambua, P.M., Ahmed, A., Li, W., Qin, X-H., 2017. Review of the Applications of Biocomposites in the Automotive Industry. Polymer Composites, Volume 38(11), pp. 2553-2569

Faruk, O., Bledzki, A.K., Fink, H-P., Sain, M., 2012. Biocomposites Reinforced with Natural Fibers: 2000-2010. Progress in Polymer Science, Volume 37(11), pp. 1552-1596

Fatra, W., Rauhilahi, H., Helwani, Z., Zulfansyah, Asmura, J., 2016. Effect of Alkaline Treatment on The Properties of Oil Palm Empty Fruit Bunch Fiber Reinforced Polypropylene Composite. International Jounal of Technology, Volume 7(6), pp. 10261034

Gurunathan, T., Mohanty, S., Nayak, S.K., 2015. A Review of the Recent Developments in Biocomposites Based on Natural Fibres and Their Application Perspectives. Composites Part A: Applied Science and Manufacturing, Volume 77, pp. 1-25 
Holbery, J., Houston, D., 2006. Natural-Fiber-Reinforced Polymer Composites in Automotive Applications. The Journal of The Minerals 58, Volume 11, pp. 80-86

Huda, MS, Drzal, L.T., Ray, D., Mohanty, A.K., Mishra, M., 2008. 7-Natural Fiber Composites in the Automotive Sector. Properties and Performance of Natural-Fibre Composites, Woodhead Publishing Series in Composites Science and Engineering. pp. 221-268

Mardiyati, Steven, Rizkiansyah, R.R., Senoaji, A., Suratman, R., 2016. Effects of Alkali Treatment on The Mechanical and Thermal Properties of Sansevieria Trifasciata Fiber. AIP Conference Proceedings, Volume 1725(1), p. 020043

Miléo, P.C., Mulinari, D.R., Baptista, C.A.R.P., Rocha, G.J.M., Gonçalves, A. R., 2011. Mechanical Behaviour of Polyurethane from Castor Oil Reinforced Sugarcane Straw Cellulose Composites. Procedia Engineering, Volume 10, pp. 2068-2073

Najafi, S.K., 2013. Use of Recycled Plastics in Wood Plastic Composites - A Review. Waste Management, Volume 33(9), pp. 1898-1905

Pickering, K. 2008. Properties and Performance of Natural-Fibre Composites. Sawston, UK: Woodhead Publishing

Pramono, A.E., Rebet, I., Zulfa, A., 2017. Electrical and Mechanical Properties of Phenolic Resin and Gigantochloa Apus Carbon Fiber Composites. International Journal of Technology, Volume 8(5), pp. 920-929

Rajak, D.K., Pagar, D.D., Menezes, P.L., Linul, E., 2019. Fiber-Reinforced Polymer Composites: Manufacturing, Properties, and Applications. Polymers, Volume 11(10), pp. 1-37

Ramesh, M., Palanikumar, K., Reddy, K.H., 2017. Plant Fibre Based Bio-Composites: Sustainable and Renewable Green Materials. Renewable and Sustainable Energy Reviews, Volume 79, pp. 558-584

Sanjay, M.R., Madhu, P., Jawaid, M., Senthamaraikannan, P., Senthil, S., Pradeep, S., 2018. Characterization and Properties of Natural Fiber Polymer Composites: A Comprehensive Review. Journal of Cleaner Production, Volume 172, pp. 566-581

Sankar, P.H., Mohana Reddy, Y.V., Hemachandra Reddy, K., Ashok Kumar, M., Ramesh, A., 2014. The Effect of Fiber Length on Tensile Properties of Polyester Resin Composites Reinforced by the Fibers of Sansevieria Trifasciata. International Letters of Natural Science, Volume 3, pp. 7-13

Sharath Shekar, H.S., Ramachandra, M., 2018. Green Composites: A Review. Materials Today: Proceedings, Volume 5(1-Part 3), pp. 2518-2526

Shieddieque, A.D., Mardiyati, Suratman, R., Widyanto, B., 2018. The Effect of Alkaline Treatment and Fiber Orientation on Impact Resistant of Bio-Composites Sansevieria Trifasciata Fiber/Polypropylene as Automotive Components Material. AIP Conference Proceedings, Volume 1945(1)

Shieddieque, A.D., Rochim Suratman. 2019. The Effect of Dibutyl Phthalate Plasticizer to Impregnation and Mechanical Properties of Biocomposite Sansevieria Trifasciata / High Impact Polypropylene The Effect of Dibutyl Phthalate Plasticizer to Impregnation and Trifasciata / High Impact Polypropyle. In: IOP Conference Series: Materials Science and Engineering, International Conference on Design and Application of Engineering Materials (IC-DAEM) in conjunction with Seminar Nasional Metalurgi dan Material XI (SENAMM) 6-7 September 2018, Bandung, Indonesia, Volume 547

Sreenivasan, V.S., Ravindran, D., Manikandan, V., Narayanasamy, R., 2011. Mechanical Properties of Randomly Oriented Short Sansevieria Cylindrica Fibre/Polyester Composites. Materials and Design, Volume 32(4), pp. 2444-2455

Sreenivasan, V.S., Ravindran, D., Manikandan, V., Narayanasamy, R.,. 2012. Influence of Fibre Treatments on Mechanical Properties of Short Sansevieria Cylindrica/Polyester Composites. Materials \& Design, Volume 37, pp. 111-121 
Suharty, N.S., Ismail, H., Diharjo, K., Handayani, D.S., Firdaus, M., 2016. Effect of Kenaf Fiber as a Reinforcement on the Tensile, Flexural Strength and Impact Toughness Properties of Recycled Polypropylene/Halloysite Composites. Procedia Chemistry, Volume 19, pp. 253-258

Surip, S.N., Jaafar, W.N.R.W., 2018. Comparison Study of the Bio-degradation Property of Polylactic Acid (PLA) Green Composites Reinforced by Kenaf Fibers. International Journal of Technology. Volume 9(6), pp. 1205-1215

Thakur, V.K., Thakur, M.K., 2014. Processing and Characterization of Natural Cellulose Fibers/Thermoset Polymer Composites. Carbohydrate Polymers, Volume 109, pp. 102117

Väisänen, T., Haapala, A., Lappalainen, R., Tomppo, L., 2016. Utilization of Agricultural and Forest Industry Waste and Residues in Natural Fiber-Polymer Composites: A Review. Waste Management, Volume 54, pp. 62-73

Venkatachalam, N., Navaneethakrishnan, P., Rajsekar, R., Shankar, S., 2016. Effect of Pretreatment Methods on Properties of Natural Fiber Composites : A Review. Polymers \& Polymer Composites, Volume 24(7), pp. 555-566

Wolela, A.D., 2019. Extraction and Characterization of Natural Cellu- Lose Fibers from Sanseveria Trifasciata Plant. Trends in Textile Engineering \& Fashion Technology, Volume 5(2), pp. 630-634

Xia, C., Shi, S.Q., Wu, Y., Cai, L., 2016. High Pressure-Assisted Magnesium Carbonate Impregnated Natural Fiber-Reinforced Composites. Industrial Crops and Products, Volume 86, pp. 16-22

You, Y.J., Kim, J-H.J., Park, K-T., Seo, D-W., Lee, T-H., 2017. Modification of Rule of Mixtures for Tensile Strength Estimation of Circular GFRP Rebars. Polymers, Volume 9(12), pp. $1-13$

Zakaria, N.E., Ahmad, I., Mohamad, W.Z.W., Baharum, A., 2018. Effects of Fibre Size on Sansevieria Trifasciata / Natural Rubber/ High Density Polyethyleme Biocomposites. Malaysian Journal of Analytical Science Volume 22(6), pp. 1057-1064 